\title{
Daucus carota pentane-based fractions arrest the cell cycle and increase apoptosis in MDA-MB-231 breast cancer cells
}

\author{
Wassim N Shebaby ${ }^{1}$, Mohammad Mroueh², Kikki Bodman-Smith ${ }^{1}$ Anthony Mansour ${ }^{3}$, Robin I Taleb ${ }^{4}$, \\ Costantine F Daher ${ }^{4}$ and Mirvat El-Sibai ${ }^{*^{*}}$
}

\begin{abstract}
Background: Daucus carota L.ssp.carota (wild carrot), an herb used in folk medicine worldwide, was recently demonstrated to exhibit anticancer activity. In this study we examined the anticancer effect of Daucus carota oil extract (DCOE) fractions on the human breast adenocarcinoma cell lines MDA-MB-231 and MCF-7 and clarified the mechanism of action.

Methods and results: Using the WST assay, the pentane fraction (F1) and 1:1 pentane:diethyl ether fraction (F2) were shown to possess the highest cytotoxicity against both cell lines. Flow cytometric analysis revealed that both fractions induced the accumulation of cells in the sub-G1 phase, increase in apoptotic cell death and chromatin condensation. The increase in apoptosis in response to treatment was also apparent in the increase in BAX and the decrease in Bcl-2 levels as well as the proteolytic cleavage of both caspase-3 and PARP as revealed by Western blot. Furthermore, treatment of MDA-MB-231 cells with either fraction significantly reduced the level of phosphorylated Erk but did not show any effect on phosphorylated Akt. The combined treatment with a potent PI3K inhibitor (wortmannin) and F1 or F2 fraction had a synergistic inhibitory effect on cell survival which shows that these two drugs work on different pathways.
\end{abstract}

Conclusions: These results suggest that the pentane-based fractions of DCOE possess potential anti-cancer activity that is mainly mediated through the Erk pathway.

Keywords: Daucus carota, Breast cancer, Proliferation, Apoptosis, PI3K, MAPK

\section{Background}

Breast cancer is one of the most common cancers among women aged between $40-55$ years, and is the leading cause of death in women globally [1]. The present treatment approaches, whether surgery, chemotherapy, immunotherapy or radiotherapy are usually accompanied with adverse effects, leaving the patient weak and vulnerable. Furthermore, acquired patient resistance to these treatments poses a continuing problem that compromises the effectiveness of anti-cancer therapy [2]. Therefore, there is a growing interest in finding more effective and selective anti-cancer remedies. The use of natural

\footnotetext{
* Correspondence: mirvat.elsibai@lau.edu.lb

${ }^{4}$ Department of Natural Sciences, School of Arts and Sciences, Lebanese

American University, P.O. Box 36, Byblos, Lebanon

Full list of author information is available at the end of the article
}

therapeutic compounds of plant origin has been of interest to researchers for the past few decades. In fact, over $25 \%$ of pharmaceutical drugs used in medicine today are derived from plants [3]. For instance, plant secondary metabolites such as terpenes, phenolics and alkaloids, are extensively exploited in cancer research [4-9]. Currently, there are four classes of plant-derived anticancer compounds in clinical use: vinca alkaloids, epipodophyllotoxins, taxanes, and camptothecin derivatives [10].

Among the hallmarks of cancer cells are aberrant cell cycle and apoptosis regulation. Cancer cells are known to lose the ability to negatively regulate the cell cycle leading to their continuous proliferation [11] and also resist apoptosis even in the presence of apoptotic stimuli [12]. Accordingly, a wide range of phytochemicals derived from medicinal plants have been reported to 
exhibit anticancer activity by targeting several signaling cascades associated with cell cycle regulation and apoptosis. These cascades include mitogenic signaling pathways, such as mitogen-activated protein kinases (MAPKs) [13], PI3K-Akt pathway [14] and nuclear kappa B pathway (NF-kB) [15]. These alterations induced by phytochemicals are eventually correlated to the modulation of cell cycle and/or apoptosis of cancer cells [16].

Wild carrot, Daucus carota L. ssp. carota, is a spinyfruited herb that grows in moderate regions throughout the world. The Daucus carota oil extract from various geographical locations constitutes mainly of monoterpenes, sesquiterpenes, and phenylpropanoids $[17,18]$. Unlike the edible carrot, Daucus carota L. ssp. sativus, few reports exist about the potential therapeutic use of the wild carrot. In European folk medicine, it is used as a urinary antiseptic and anti-inflammatory remedy for cystitis and prostatitis [19]. The plant has also been reported to possess antilithic, diuretic, [20,21] antibacterial, and antifungal activities [18,22,23]. Recent studies conducted in our laboratories, showed that Daucus carota oil extract (DCOE) exhibited anti-tumor [24,25], antioxidant [24], anti-inflammatory, and anti-ulcer [26] activities. The present study aims to evaluate the anticancer activity of DCOE fractions against MDA-MB-231 and MCF-7 human breast cancer cell lines and to elucidate possible mechanisms of action.

\section{Methods \\ Reagents}

Dulbecco's modified Eagle's medium (DMEM) and dimethyl sulfoxide (DMSO) were purchased from Sigma (St. Louis, USA). The Annexin V/PI apoptosis detection kit was purchased from Abcam (Cambridge, UK), and WST-1 reagent was purchased from Roche (Mannheim, Germany). All other chemicals used in this study were purchased from Sigma (St. Louis, USA) unless otherwise stated.

\section{Sample collection and oil extraction}

Daucus carota (Linnaeus) ssp. carota mature umbels were collected at the post flowering season between May and August from Byblos, Lebanon. The plant was identified according to the characteristics described in the "Handbook of Medicinal Herbs" [21] and confirmed by Dr. A. Houri, a Lebanese plant expert at the Lebanese American University. A voucher specimen of the plant material used in this study has been deposited in a publicly available herbarium. The extraction procedure was carried out according to the method described by Zeinab et al. [25]. Briefly, umbels were air dried in the shade and then cut into small pieces for oil extraction in methanol/ acetone (1:1) for $72 \mathrm{~h}$. The extract was then filtered and evaporated to dryness under reduced pressure. The residue was centrifuged and the oil was dried over anhydrous sodium sulfate. The final yield $(3.47 \%)$ was stored in a closed amber bottle at $4^{\circ} \mathrm{C}$ until use.

\section{DCOE fractionation}

Thirty grams of $D C O E$ were chromatographed on a silica gel column (35-70 mesh). The first fraction (F1) was eluted with pentane (100\%), the second fraction (F2) with pentane: diethyl ether (50:50), the third fraction (F3) with diethyl ether (100\%) and the fourth fraction (F4) with chloroform: methanol (93:7). Fractions were analyzed by TLC using hexane: ethyl acetate (70:30) as mobile phase and plates were stained with $2 \%$ anisaldehyde.

\section{Cell lines and culture}

Human breast adenocarcinoma cell lines MDA-MB231 and MCF-7 were purchased from American Type Culture Collection (ATCC, Rockville). Both cell lines were cultured in a humidified incubator at $37^{\circ} \mathrm{C}$ and $5 \%$ $\mathrm{CO}_{2}$ atmosphere in DMEM (Dulbecco's modified Eagle's medium), supplemented with $10 \%$ fetal bovine serum and $1 \%$ Penicillin-streptomycin.

\section{Cell proliferation assay}

The proliferation of the MDA-MB-231 and MCF-7 cells was tested using WST-1 assay. Cells were plated in 96well plates at a concentration of $10^{5} \mathrm{cell} / \mathrm{ml}$ for $24 \mathrm{~h}$. Both cell lines were then treated with increasing concentrations $(10,25,50$, and $100 \mu \mathrm{g} / \mathrm{ml})$ of the four DCOE fractions in DMSO for $48 \mathrm{~h}$. At the end of the treatment period, WST-1 reagent was added to the cells and incubated in a humidified incubator at $37^{\circ} \mathrm{C}$ and $5 \% \mathrm{CO}_{2}$ atmosphere for $3 \mathrm{~h}$. The intensity of the produced formazan was quantified at $450 \mathrm{~nm}$ using a microplate ELISA reader. For wortmannin treatment, MDA-MB231 cells were incubated with or without wortmannin $(1 \mu \mathrm{M})$ for $1 \mathrm{~h}$ in a serum-free complete MEM prior to treating cells with 25 and $50 \mu \mathrm{g} / \mathrm{ml}$ of F1 and F2 fractions for $48 \mathrm{~h}$.

\section{Apoptosis assay}

The apoptotic effect of the most potent fractions F1 and F2 of DCOE on MDA-MB-231 cells was determined by Annexin V-FITC staining assay and measured by C6 flow cytometer (BD Accuri Cytometers, Ann Arbor, MI USA). The MDA-MB-231 cells $\left(1 \times 10^{5}\right.$ cells $\left./ \mathrm{ml}\right)$ were treated with different concentrations ( 25 and $50 \mu \mathrm{g} / \mathrm{ml}$ ) of both fractions and cultured in 6-well plates for $48 \mathrm{~h}$. Treated cells were harvested, washed with phosphate-buffer saline (PBS) and then centrifuged at $500 \mathrm{~g}$ for $5 \mathrm{~min}$. Then cell pellet was suspended in $500 \mu \mathrm{L}$ of Annexin V-FITC/ $\mathrm{PI}$ apoptosis detection kit at room temperature for $5 \mathrm{~min}$ in the dark. Annexin V-FITC binding was analyzed by flow cytometry $(E x=488 \mathrm{~nm} ; \mathrm{Em}=530 \mathrm{~nm})$ FL1 channel 
for detecting Annexin V-FITC staining and FL3 channel for detecting PI staining. Annexin V-positive, PI-negative cells were scored as early apoptotic, and double-stained cells were considered as late apoptotic.

\section{DAPI and annexin V staining}

MDA-MB-231 cells were seeded on $25 \mathrm{~mm}$ square glass cover slips. After treatment, cells were washed with PBS and fixed with $3.7 \%$ paraformaldehyde for $10 \mathrm{~min}$ at room temperature. Fixed cells were permeabilized with a $0.1 \%$ solution of Triton X-100 in PBS and then stained by Annexin V conjugated to FITC or with $1 \mu \mathrm{g} / \mathrm{ml}$ of DAPI solution for $20 \mathrm{~min}$. The cells were washed with PBS and observed with fluorescence microscope.

\section{Cell cycle analysis}

The effect of F1 and F2 fractions on cell cycle distribution was assessed by flow cytometry after staining the MDA-MB-231 cells with propidium iodide (PI). Briefly, the MDA-MB-231 cells $\left(1 \times 10^{5}\right.$ cells $\left./ \mathrm{ml}\right)$ were treated with different concentrations $(25$ and $50 \mu \mathrm{g} / \mathrm{ml}$ ) of both fractions for $48 \mathrm{~h}$. The treated cells were harvested, washed with PBS and fixed with $70 \%$ ethanol on ice. Then cells washed with cold PBS, suspended in $200 \mu \mathrm{L}$ $1 \mathrm{X}$ Propidium Iodide + RNase staining solution and incubate at $37^{\circ} \mathrm{C}$ in the dark for 30 minutes. Propidium Iodide Flow Cytometry Kit was used for cell cycle analysis. DNA content of the cells was measured by C6 flow cytometer and the population of each phase was determined using CFlow Plus analysis software (BD Accuri Cytometers, Ann Arbor, MI USA).

\section{Western blot}

MDA-MB-231 cells were treated with different concentrations of F1 and F2 (25 and $50 \mu \mathrm{g} / \mathrm{ml})$ for $48 \mathrm{~h}$. The adherent and non-adherent MDA-MB-231 cells were collected on ice, washed twice with PBS, lysed with lysis buffer, and centrifuged at $12,000 \mathrm{~g}$ for $10 \mathrm{~min}$ at $4^{\circ} \mathrm{C}$. The cell lysate was heated at $100^{\circ} \mathrm{C}$ for $5 \mathrm{~min}$, and the protein content was determined by the Bio-Rad protein assay (Bio-Rad, Hercules, CA, USA). The same amount of proteins was loaded to a $10 \%$ SDS-PAGE. Proteins were then transferred to PVDF membrane (Pall Corporation, Ann Arbor, USA) and blocked with 5\% skim milk for $2 \mathrm{~h}$. The membranes were probed with primary antibodies against Actin, p53, Bcl-2, Bax, Caspase-3, PARP, Akt, p-Akt, Erk, and p-Erk (Abcam, Cambridge, USA) at $4^{\circ} \mathrm{C}$ overnight. Later, the primary antibodies were washed away with TBST for $1 \mathrm{~h}$ and the membranes were treated with HRP-coupled secondary antibodies (Promega Corp., Madison, USA) for $1 \mathrm{~h}$, and washed with TBST afterwards. Finally, Detection of each protein was performed using the ECL kit (Abcam plc, 330 Cambridge Science Park, Cambridge UK).

\section{Statistical analysis}

Data was analyzed for statistical significance using one way analysis of variance (ANOVA). Values of the different tested parameters within each group are presented as mean \pm SEM. Significant main effect differences were tested using Bonferroni post hoc test for multiple comparisons. All data were analyzed with the statistical package SPSS 18, and differences between groups were considered statistically significant if $\mathrm{p}<0.05$.

All experimental protocols were approved by the Animal Ethical Committee of the Lebanese American University, which complies with the Guide for the Care and Use of Laboratory Animals (Committee for the Update of the Guide for the Care and Use of Laboratory Animals, 2010).

\section{Results}

MDA-MB-231 and MCF-7 breast cancer cells were treated with different concentrations of fractions $1,2,3$, and 4 of DCOE for $48 \mathrm{~h}$ (Figure 1). The treatment with the extract appeared to be dose-dependent with maximum inhibition of proliferation at higher concentrations (50 and $100 \mu \mathrm{g} / \mathrm{ml}$ ). MCF-7 cells showed the least responsiveness to the extract when compared to its more malignant counterpart the MDA-MB-231 cell line. The $\mathrm{IC}_{50}$ values of the four fractions at $48 \mathrm{~h}$ were $22,32,48$, and $43 \mu \mathrm{g} / \mathrm{ml}$ for MCF-7 and 17, 11, 27, and $23 \mu \mathrm{g} / \mathrm{ml}$ for MDA-MB-231. The pentane fraction (F1) and pentane/diethyl fraction (F2) showed the highest cytotoxicity against both cell lines with the lowest $\mathrm{IC}_{50}$ (Additional file 1: Table S1).

To determine whether growth inhibition by F1 and F2 on MDA-MB-231 human breast cancer cells was due to cell cycle arrest or apoptosis, the cells were stained with PI after permeabilization to look at the cell cycle profile or with Annexin and PI to look for apoptosis. As shown in Figure 2, treatment of MDA-MB-231 with F1 and F2 (25 and $50 \mu \mathrm{g} / \mathrm{ml}$ ) for $48 \mathrm{~h}$ resulted in the increase of cell percentage in the sub-G1 phase with hypodiploid nuclei, indicating that both fractions could cause DNA fragmentation. This increase was coupled with the decreased percentage of cells in the $S$ and $G 2 / M$ phases. Figure 3 showed that cells treated with $25 \mu \mathrm{g} / \mathrm{ml} \mathrm{F1}$ or F2 were in early apoptosis whereas cells treated with $50 \mu \mathrm{g} / \mathrm{ml}$ went into late apoptosis. To further confirm the apoptotic effect of F1 and F2, control and treated MDAMB-231 cells were stained with DAPI and annexin. Condensation of chromatin in nuclei was evident in cells treated with either dose of F1 (Figure 4A). Besides, annexin staining showed that both fractions induced the phosphatidylserine (PS) translocation in the cell membrane which is indicative of apoptosis followed by membrane leakage (Figure 4B).

To explore the mechanism by which F1 and F2 induced apoptosis, the expression levels of various pro- 


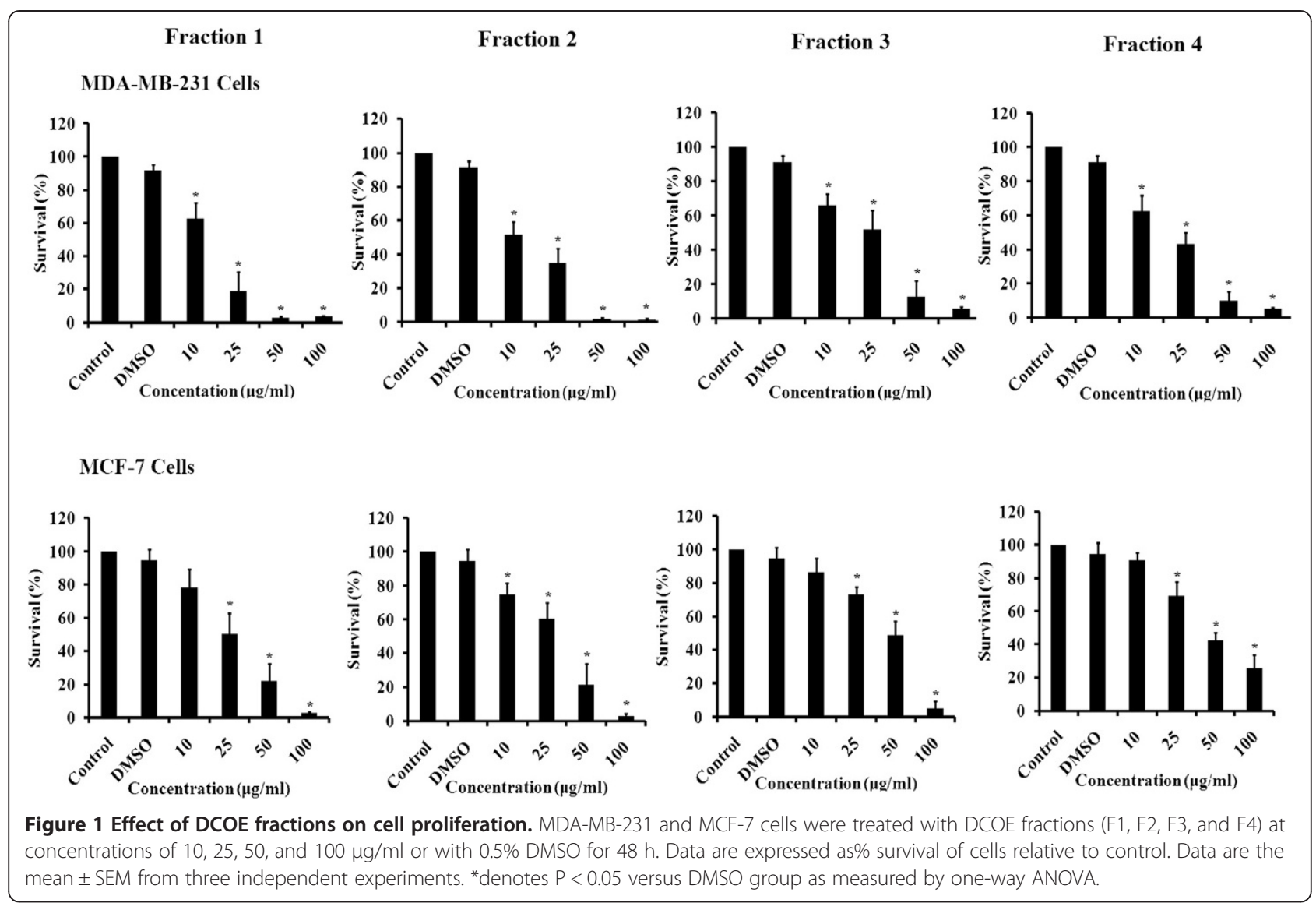

A
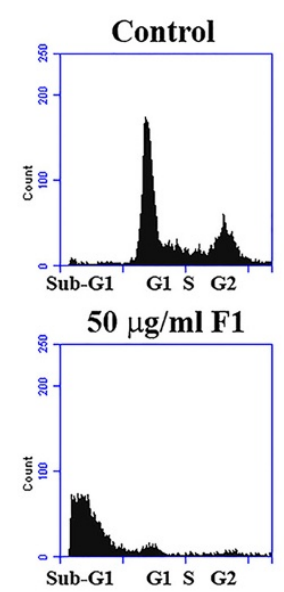
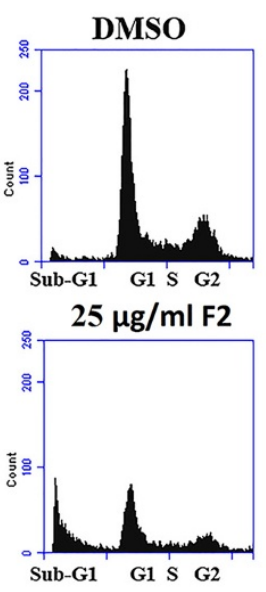

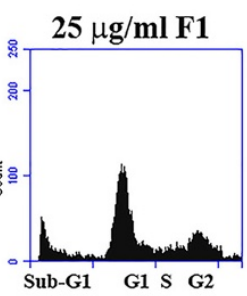

$50 \mu \mathrm{g} / \mathrm{ml} \mathrm{F2}$

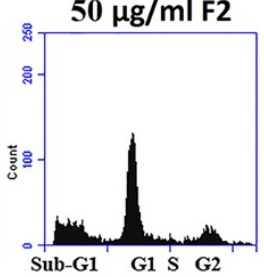

B

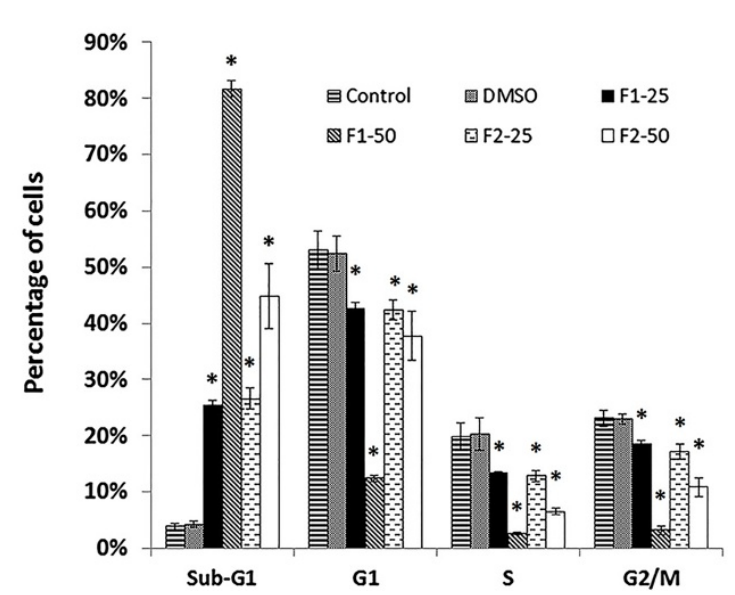

Figure 2 Effect of F1 and F2 fractions on the cell cycle distribution in MDA-MB-231. (A) MDA-MB-231 cells were treated with 25 and 50 $\mu \mathrm{g} / \mathrm{ml}$ of F1 or F2 fractions and control cells were treated with $0.5 \%$ DMSO for 48 hours, after which cells were stained with PI and analyzed for DNA content by flow cytometry. The sub-G1 peak is considered as the apoptotic portion. The results shown are representative of 3 independent experiments. (B) Bar graph shows the cell distributions of each phase of the cell cycle. Data are means \pm SEM of three independent experiments. *denotes $P<0.05$ versus DMSO group as measured by one-way ANOVA. 


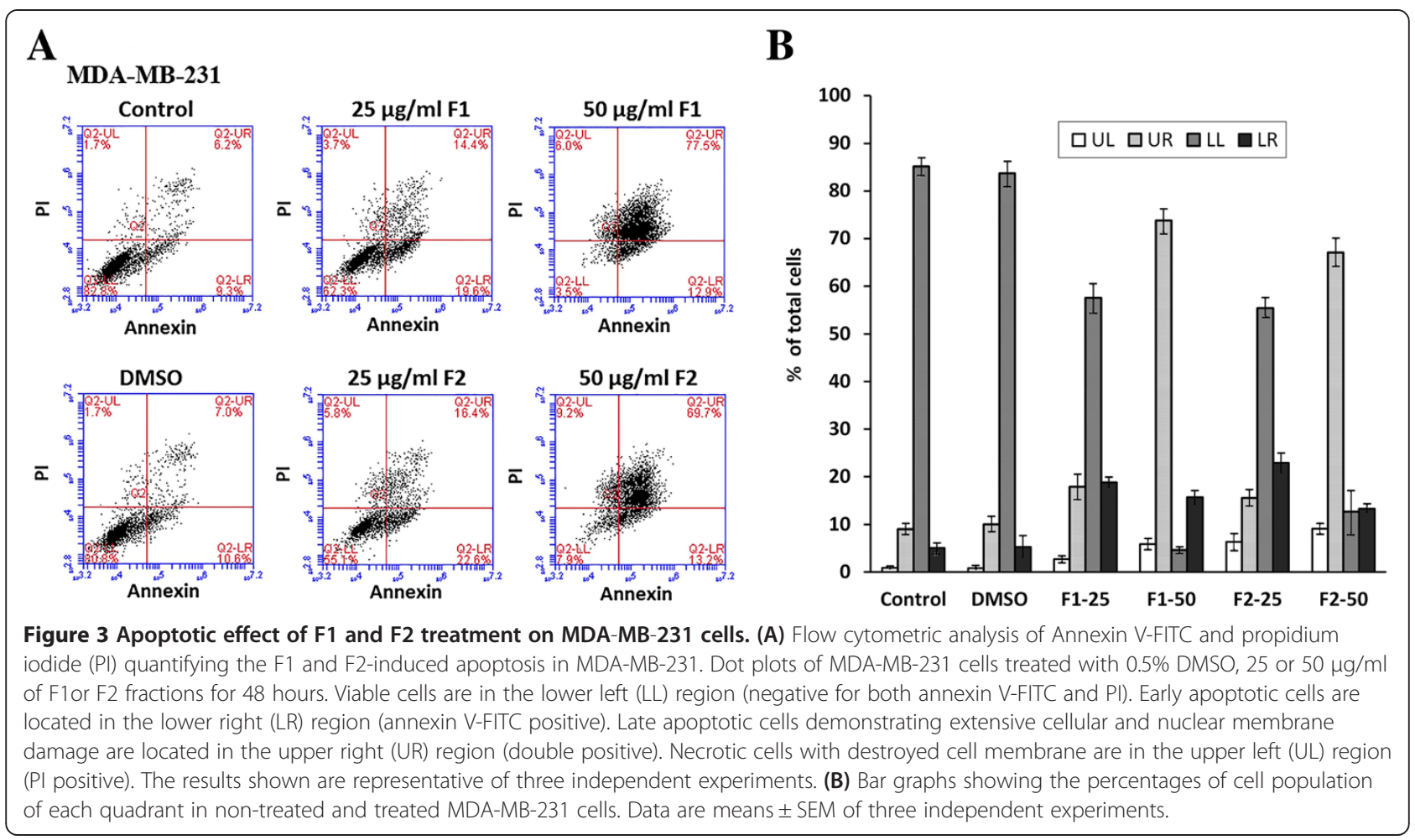

apoptotic and anti-apoptotic proteins was evaluated by western blot. Treatment of MDA-MB-231 cells with F1 and F2 induced a decrease in the level of the inactive caspase- 3 in a dose dependent manner indicating its cleavage into activated form. In response to treatment, the level of the 116-kDa PARP decreased and the level of the cleaved $85-\mathrm{kDa}$ fragment increased (Figure 5A). Furthermore, the results of western blot indicated that the level of the anti-apoptotic protein Bcl-2 was decreased, whereas the pro-apoptotic protein BAX was increased. The expression of $\mathrm{p} 53$ protein was also assessed by western blot and showed an increased level as shown in Figure 5A.
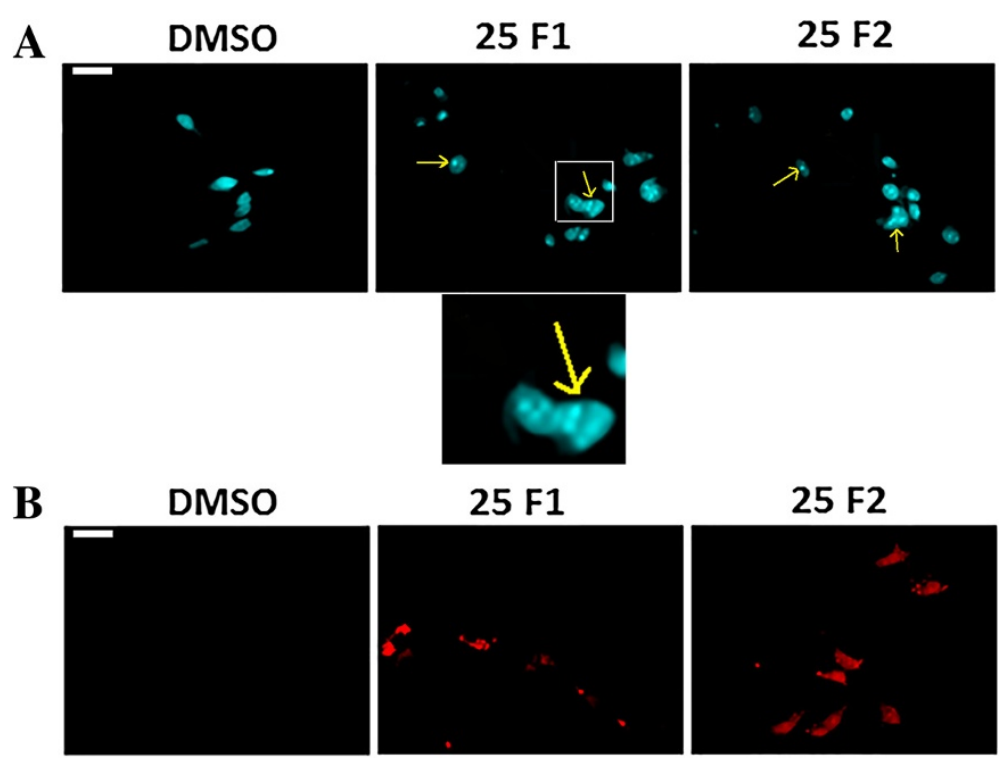

Figure 4 Apoptotic morphological changes of MDA-MB-231 cells following treatment with fractions F1 or F2. Fluorescent micrographs of control (0.5\% DMSO) and MDA-MB-231cells treated with $25 \mu \mathrm{g} / \mathrm{ml}$ of F1 or F2 fractions for 48 hours and stained with DAPI (A) or annexin (B) and examined by fluorescence microscopy. Arrows in $\mathbf{A}$ indicate apoptotic bodies of nuclear fragmentation. Scale bar is $10 \mu \mathrm{m}$. 

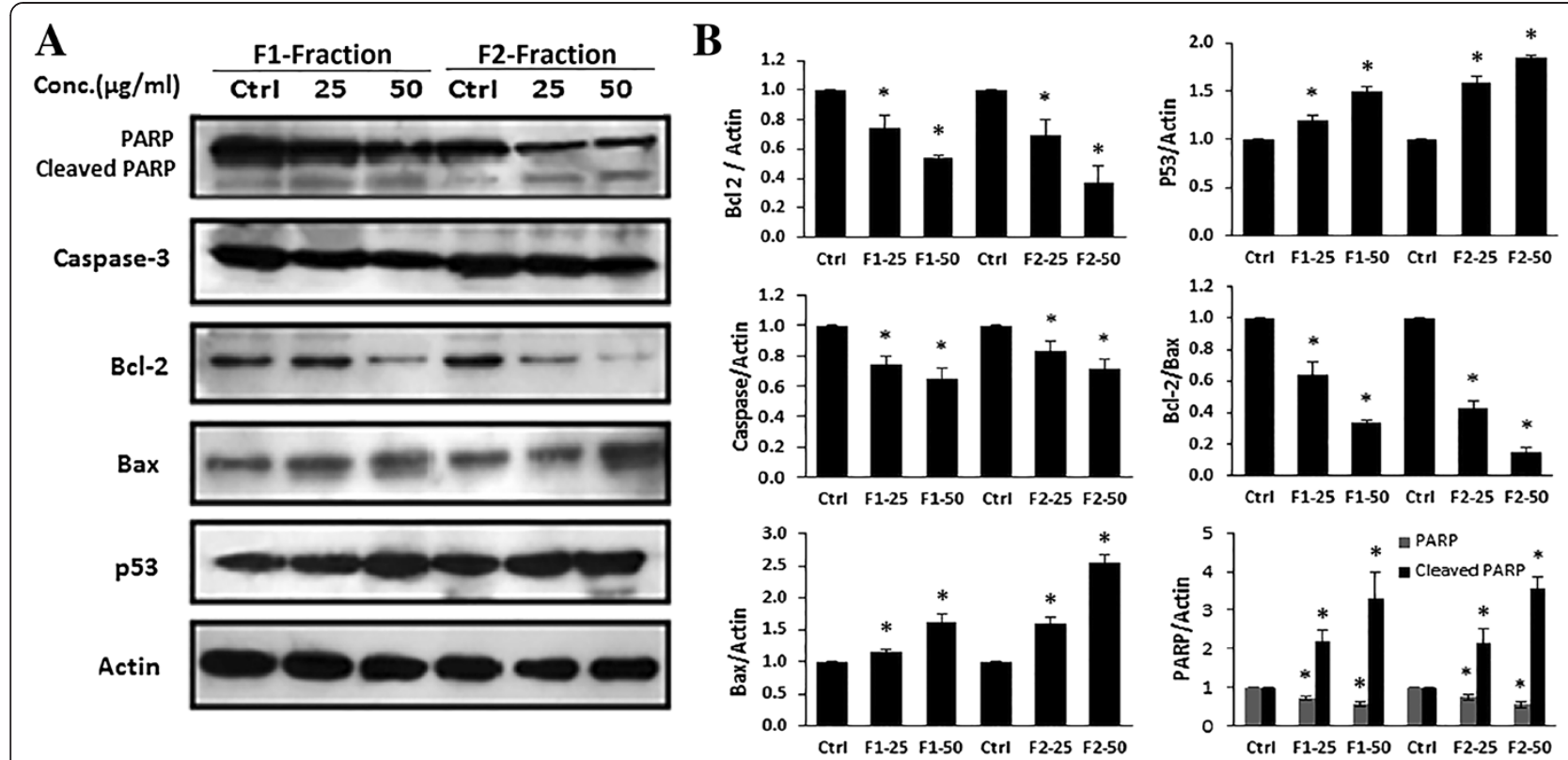

Figure 5 Western blot analysis of apoptosis related proteins in MDA-MB-231 cells. (A) Effect of F1 and F2 fractions on the expression of PARP, p53, caspase-3, Bcl-2, and Bcl2-associated X (BAX) proteins. Expression of $\beta$-actin was used as an internal control. MDA-MB-231 cells were treated with 25 and $50 \mu \mathrm{g} / \mathrm{ml}$ of F1 or F2 fractions and control cells were treated with $0.5 \%$ DMSO for 48 hours. Western blots are representative of three independent experiments. (B) The densitometer-intensity data of the proteins of each blot is presented as mean \pm SEM from three independent experiments. *denote $\mathrm{P}<0.05$ versus control $(0.5 \% \mathrm{DMSO})$ as measured by one-way ANOVA.

PI3K activation was examined using western blot analysis to look for phosphorylated Akt. Upon treatment of MDA-MB-231 with either fraction, no significant change in phosphorylated Akt was observed as compared with the control (Figure 6). On the other hand, the activity of the MAPK pathway was assessed through examining the level of phosphorylation of Erk. Results in Figure 6 revealed a significant decrease in pErk upon treatment with F1 or F2.

Since neither fraction acted through the PI3K pathway in MDA-MB-231 cells, we investigated whether the combined treatment of each fraction with wortmannin, a selective PI3K inhibitor, would have a synergistic effect on the inhibition of cell proliferation. WST results showed a substantial decrease in cell survival of MDAMB-231 cells treated with $25 \mu \mathrm{g} / \mathrm{ml}$ of F1 or F2 along with wortmannin $(1 \mu \mathrm{M})$ compared to fraction alone (Figure 7A and B).

\section{Discussion}

DCOE has been shown to have an antioxidant and anticancer activities against breast and colon cancer cell lines [24]. Previously, DCOE has been fractionated into four major fractions and various constituents of each

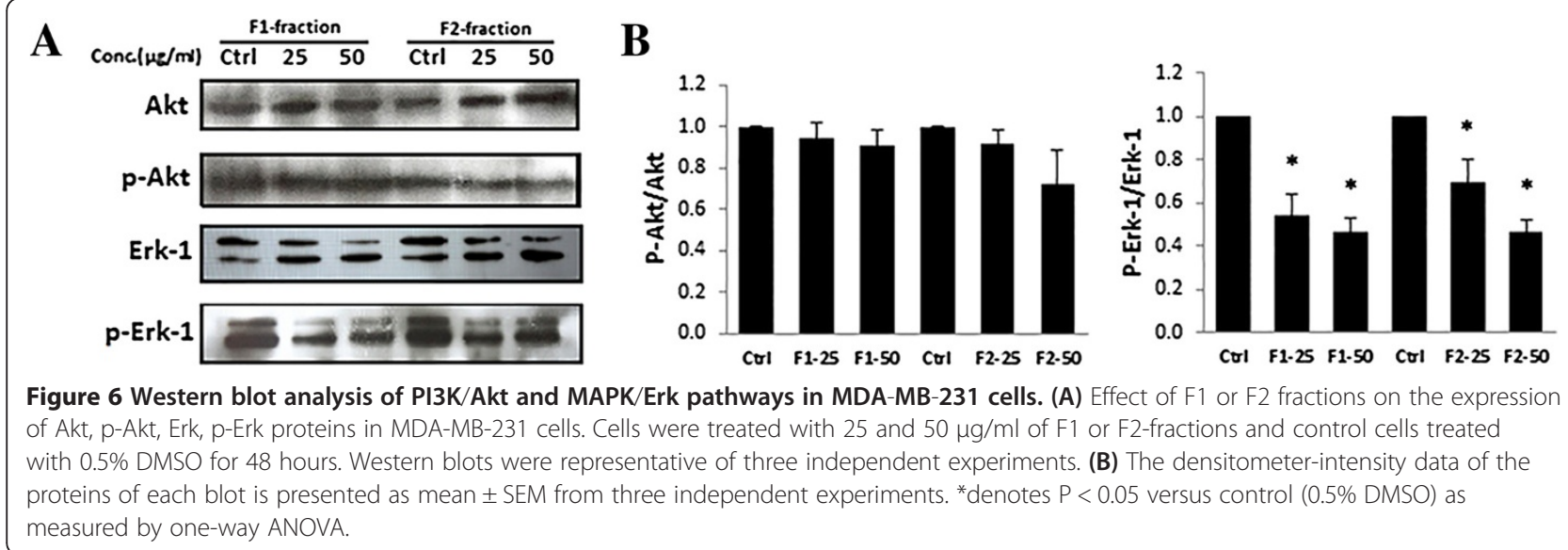




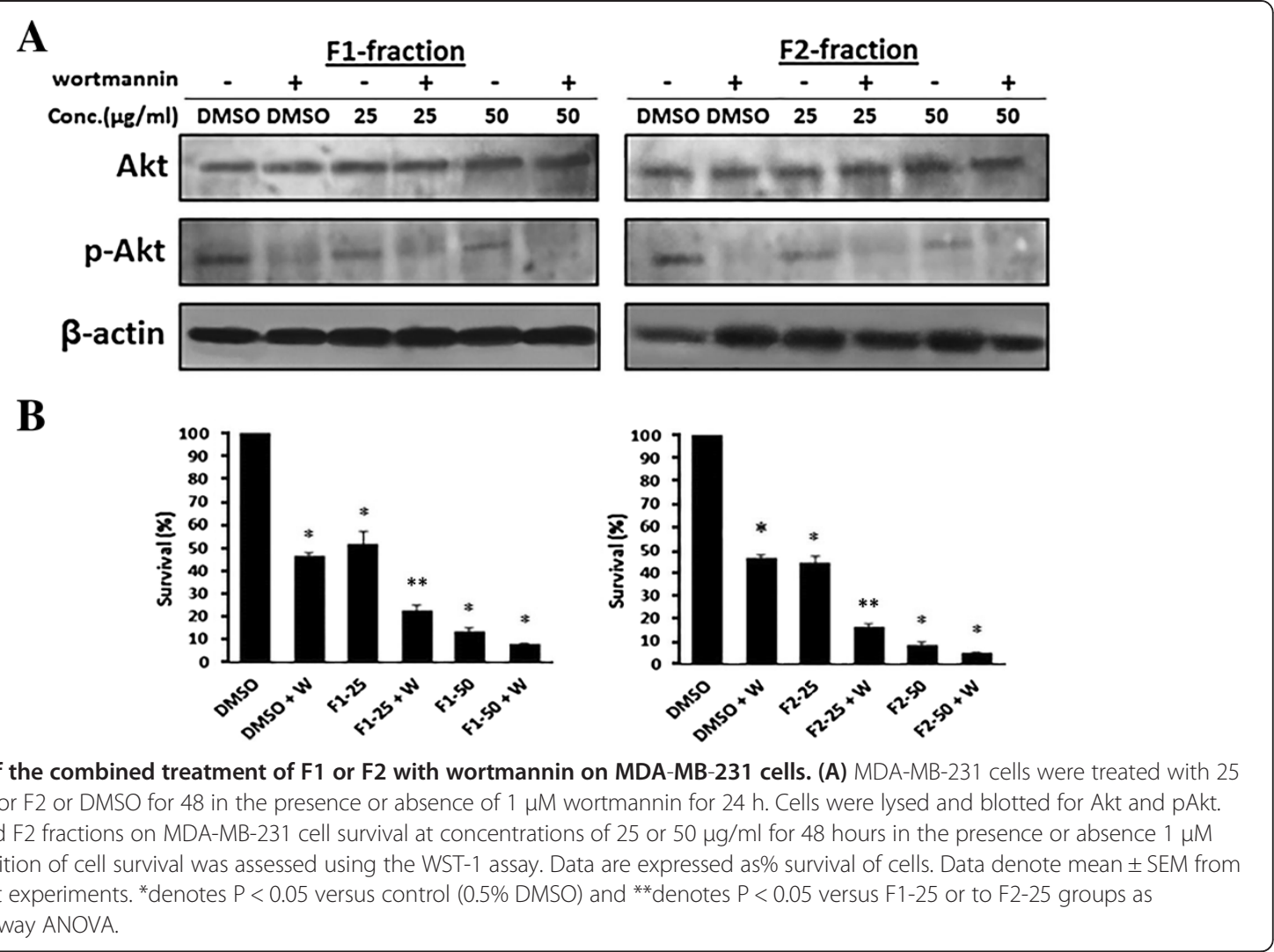

fraction were identified and their in vitro and in vivo antioxidant activities were evaluated (Shebaby, et al. 2013, submitted). The present data demonstrated that the DCOE fractions had significant anti-proliferative effect against MDA-MB-231 and MCF-7 human breast cancer cell lines. The DCOE fractions exhibited dose dependent cytotoxicity against both cell lines. Moreover, pentane (F1) and pentane/diethyl ether (F2) fractions exhibited higher anticancer activity than the other fractions (F3, F4).

This anticancer activity might be attributed to major components present in the oil fractions. For example, $\alpha$-humulene and $\beta$-caryophyllene which are major components of $\mathrm{F} 1$, have been reported to exhibit cytotoxic activity against several human cell lines $[27,28]$. Similarly, the sesquiterpene $\beta$-selinene and the phenylpropanoids, $(E)$-methylisoeugenol and elemicin, identified in F2 fraction are also known to demonstrate antiproliferative activity and tumoricidial effects against several human cell lines [8]. The anti-proliferative activity of the F2 fraction may be attributed to the presence of the major compound which is tentatively identified via GC-MS as 2-himachalene-6-ol. To the best of our knowledge, this compound has not been reported in any of the wild carrot species around the world and there are no previous studies involving its anticancer activity.
However, widdrol, a structural isomer of 2-himachalen6-ol, extracted from Juniperus chinensis, has been shown to exhibit a potent anti-cancer activity against colon adenocarcinoma cells HT29 by inhibiting their proliferation and inducing cell cycle G1 arrest [29]. In another study, widdrol induced G1 arrest through the induction of Chk2, p53 phosphorylation and CDK inhibitor p21 expression as well as inhibition of cyclin E, cyclin-dependent kinase (CDK2) and retinoblastoma protein (pRB) [30].

Targeting the cell cycle and apoptotic pathways in cancer cells is an important approach for cancer treatment and anti-cancer drug development [31]. Therefore, many studies have been conducted to isolate and identify compounds that induce cell cycle arrest and apoptosis [32]. In this study, we found that fractions F1 and F2 induced apoptosis in MDA-MB-231 cells, as verified by the formation of apoptotic nuclei that are characterized by chromatin condensation and DNA fragmentation. These results are consistent with an accumulation of cells in the sub-G1 apoptotic phase. The cell cycle analysis also revealed a decrease in cycling cells, which is indicative of cell cycle arrest. The tumor suppressor p53 plays an important role in response to DNA damage or other genomic instability. Functional p53 protein is crucial in p53-dependent pathway leading to cell cycle arrest or apoptosis [33]. MDA-MB-231 cells are known to harbor 
high level of mutant and non-functional form of p53 [34]. The increase in p53 protein following F1 or F2 treatment may not solely explain p53-dependent apoptosis. Therefore, the cell cycle arrest and apoptosis in MDA-MB-231 cells is chiefly mediated through a p53independent mechanism.

To gain an understanding into the mechanisms controlling apoptosis induced by F1 and F2, we examined several components of the apoptotic pathways. The proteins of the $\mathrm{Bcl}-2$ family play an essential role in apoptosis and are considered as a target for anticancer therapy $[35,36]$. The Bcl-2 protein exhibits an antiapoptotic effect while BAX is a pro-apoptotic protein of the Bcl-2 family $[37,38]$. Several studies indicated that the ratio of $\mathrm{Bcl}-2$ to $\mathrm{BAX}$ proteins decreases during apoptosis [39]. In the present study, a decrease in the expression $\mathrm{Bcl}-2$ and an increase in the expression of BAX were observed after treating MDA-MB-231 cell lines with F1 and F2. Additionally, activated caspase 3 plays a crucial role in the final step of apoptosis and it is a key protease for the cleavage of PARP resulting in the loss of its enzymatic activity during apoptosis. This nuclear enzyme is involved in DNA repair and maintenance of genomic integrity and it has been used as an important marker of apoptosis [40]. The present data demonstrate that cleavage of caspase 3 and PARP are evident after treatment of MDA-MB-231 cells with F1 and F2 [41] which is consistent with an increase in apoptosis.

The MAPK/ERK pathway plays an important role in several cellular processes such as cell survival, cell proliferation and apoptosis. It is reported that constitutively activated ERK is responsible for high levels of cell growth in various cancers [42,43]. On the other hand, down-regulation of ERK activity is highly associated with apoptosis [44]. In the present study, treatment of MDAMB-231 cells with either F1 or F2 significantly decreased the phosphorylated ERK. Therefore, induction of apoptosis in MDA-MB-231 cells after F1 or F2 treatment may be mediated through the inhibition of the MAPK pathway.

The PI3K/AKT is another important intracellular signaling pathway in regulating cell proliferation and apoptosis. The serine/threonine protein kinase Akt is a downstream molecule which is involved in the inactivation of several pro-apoptotic proteins and the activation of anti-apoptotic proteins. The Akt pathway has an essential role in regulating cell proliferation and survival in cancer $[45,46]$. Our results revealed that apoptotic concentrations of the F1 or F2 did not show any significant effect on phosphorylated Akt compared to the control. However, a combined treatment with a potent PI3K inhibitor (wortmannin) had a synergistic effect on apoptosis potentially through the inhibition of both MAPK and PI3K pathways. This shows that wortmannin and the fractions are acting distinct pathways.

\section{Conclusion}

The present study demonstrates that the pentane fraction (F1) and pentane/diehtylether fraction (F2) have potent anticancer activity against MDA-MB-231 and MCF-7 human breast cancer cells. Both fractions inhibit cell proliferation by inducing cell cycle arrest and apoptosis in MDA-MB-231 cells. This induction of apoptosis is through the inhibition of the ERK pathway. The results suggest that the wild carrot could be considered a potential source for natural anticancer compounds. Future work will focus on isolation and characterization of the tentatively identified major compound and will explore the prospective in vitro and in vivo anticancer capabilities.

\section{Additional file}

Additional file 1: Table $\mathbf{S 1} . \mathrm{IC}_{50}$ values of the different fractions.

\section{Competing interests}

The authors declare that they have no competing interests.

\section{Authors' contributions}

WS performed most of the experimental work in this study. MM designed the extraction procedure. KB-S helped with the cell cycle analysis. AM helped with the experiments. RT performed the fractionation of the crude oil. CD had a lot of intellectual input. MS conceived the study. All authors read and approved the final manuscript.

\section{Acknowledgements}

This study has been funded by the Natural Science department at the Lebanese American University.

\section{Author details}

'Department of Microbial and Cellular Sciences, Faculty of Health and Medical Sciences, University of Surrey, Surrey, UK. ${ }^{2}$ School of Pharmacy, Lebanese American University, P.O. Box 36, Byblos, Lebanon. ${ }^{3}$ School of Medicine, Lebanese American University, Byblos, Lebanon. ${ }^{4}$ Department of Natural Sciences, School of Arts and Sciences, Lebanese American University, P.O. Box 36, Byblos, Lebanon.

\section{Received: 14 February 2014 Accepted: 1 October 2014}

Published: 10 October 2014

\section{References}

1. Jemal A, Bray F, Center MM, Ferlay J, Ward E, Forman D: Global cancer statistics. CA Cancer J Clin 2011, 61(2):69-90

2. Luqmani Y: Mechanisms of drug resistance in cancer chemotherapy. Med Princ Pract 2008, 14(Suppl. 1):35-48.

3. Ma JK, Chikwamba R, Sparrow P, Fischer R, Mahoney R, Twyman RM: Plant-derived pharmaceuticals-the road forward. Trends Plant Sci 2005, 10(12):580-585.

4. Reddy L, Odhav B, Bhoola KD: Natural products for cancer prevention: a global perspective. Pharmacol Ther 2003, 99(1):1-13.

5. Mumper RJ: Plant phenolics. Molecules 2010, 15:7313-7352.

6. Akahane $\mathrm{S}$, Kamata H, Yagisawa H, Hirata H: A novel neutral amino acid transporter from the hyperthermophilic archaeon Thermococcus sp. KS-1. J Biochem 2003, 133(2):173-180.

7. Jie Houa TS, Jun H, Shuangyang C, Xiaoqiang C, Guolin Z: Chemical composition, cytotoxic and antioxidant activity of the leaf essential oil of Photinia serrulata. Food Chem 2007, 103(2):355-358.

8. Andrea L, Medina-Holguín FOH, Sandra M, Sondra G, Simon JA, O'Connell MA: Chemotypic Variation of Essential Oils in the Medicinal Plant, Anemopsis californica. Phytochemistry 2008, 69(4)):919-927.

9. Sibanda S, Chigwada G, Poole M, Gwebu ET, Noletto JA, Schmidt JM, Rea Al, Setzer WN: Composition and bioactivity of the leaf essential oil of 
Heteropyxis dehniae from Zimbabwe. J Ethnopharmacol 2004, 92(1):107-111.

10. Cragg GM, Newman DJ: Plants as a source of anti-cancer agents. J Ethnopharmacol 2005, 100(1):72-79.

11. Vermeulen K, Van Bockstaele DR, Berneman ZN: The cell cycle: a review of regulation, deregulation and therapeutic targets in cancer. Cell Prolif 2003, 36(3):131-149.

12. Kaufmann $\mathrm{SH}$, Gores GJ: Apoptosis in cancer: cause and cure. Bioessays 2000, 22(11):1007-1017.

13. Sharma $Y$, Agarwal $C$, Singh AK, Agarwal R: Inhibitory effect of silibinin on ligand binding to erbB1 and associated mitogenic signaling, growth, and DNA synthesis in advanced human prostate carcinoma cells. Mol Carcinog 2001, 30(4):224-236

14. Mujoo K, Haridas V, Hoffmann JJ, Wächter GA, Hutter LK, Lu Y, Blake ME, Jayatilake GS, Bailey D, Mills GB: Triterpenoid saponins from Acacia victoriae (Bentham) decrease tumor cell proliferation and induce apoptosis. Cancer Res 2001, 61(14):5486-5490.

15. Singh S, Aggarwal BB: Activation of transcription factor NF-KB is suppressed by curcumin (diferuloylmethane). J Biol Chem 1995, 270(42):24995-25000.

16. Mo H, Elson CE: Apoptosis and cell-cycle arrest in human and murine tumor cells are initiated by isoprenoids. J Nut 1999, 129(4):804-813.

17. Gonny M, Bradesi P, Casanova J: Identification of the components of the essential oil from wild Corsican Daucus carota L. using 13C-NMR spectroscopy. Flavour Frag J 2004, 19(5):424-433.

18. Staniszewska M, Kula J, Wieczorkiewicz M, Kusewicz D: Essential oils of wild and cultivated carrots-the chemical composition and antimicrobial activity. J Essent Oil Res 2005, 17(5):579-583.

19. Hoffman D: The New Holistic Herbal 3rd Ed edn. Great Britain: Element Shaftesbury Dorset; 1990

20. Thomas KJ, Nicholl JP, Coleman P: Use and expenditure on complementary medicine in England: a population based survey. Complement Ther Med 2001, 9(1):2-11.

21. Wyk B-EV, Wink M: Medicinal plants of the world: an illustrated scientific guide to important medicinal plants and their uses. Portland, Ore, USA: Timber Press; 2004.

22. Maxia A, Marongiu B, Piras A, Porcedda S, Tuveri E, Goncalves MJ, Cavaleiro C, Salgueiro L: Chemical characterization and biological activity of essential oils from Daucus carota L. subsp. carota growing wild on the Mediterranean coast and on the Atlantic coast. Fitoterapia 2009, 80(1):57-61.

23. Rossi PG, Bao L, Luciani A, Panighi J, Desjobert JM, Costa J, Casanova J, Bolla JM, Berti L: (E)-Methylisoeugenol and elemicin: antibacterial components of Daucus carota L. essential oil against Campylobacter jejuni. J Agric Food Chem 2007, 55(18):7332-7336.

24. Shebaby WN, El-Sibai M, Smith KB, Karam MC, Mroueh M, Daher CF: The antioxidant and anticancer effects of wild carrot oil extract. Phytother Res 2013, 27(5):737-744

25. Zeinab RA, Mroueh M, Diab-Assaf M, Jurjus A, Wex B, Sakr A, Daher CF: Chemopreventive effects of wild carrot oil against 7, 12-dimethyl benz (a) anthracene-induced squamous cell carcinoma in mice. Pharm Biol 2011, 49(9):955-961.

26. Wehbe K, Mroueh M, Daher CF: The potential role of Daucus carota aqueous and methanolic extracts on inflammation and gastric ulcers in rats. J Complement Integr Med 2009, 6(1):1553-3840.

27. Cole RA, Haber WA, Setzer WN: Chemical composition of essential oils of seven species of Eugenia from Monteverde. Costa Rica Biochem Syst Ecol 2007, 35(12):877-886.

28. Silva SL, Chaar JS, Figueiredo PMS, Yano T: Cytotoxic evaluation of essential oil from Casearia sylvestris Sw on human cancer cells and erythrocytes. Acta Amazon 2008, 38(1):107-112.

29. Kwon $\mathrm{H}-J$, Lee $E-W$, Hong $Y-K$, Yun $H-J$, Kim B-W: Widdrol from Juniperus chinensis induces apoptosis in human colon adenocarcinoma HT29 cells. Biotechnol Bioprocess Eng 2010, 15(1):167-172.

30. Kwon HJ, Hong YK, Park C, Choi YH, Yun HJ, Lee EW, Kim BW: Widdrol induces cell cycle arrest, associated with MCM down-regulation, in human colon adenocarcinoma cells. Cancer Lett 2010, 290(1):96-103.

31. Hu W, Kavanagh JJ: Anticancer therapy targeting the apoptotic pathway. Lancet Oncol 2003, 4(12):721-729.

32. Kim R: Recent advances in understanding the cell death pathways activated by anticancer therapy. Cancer 2005, 103(8):1551-1560.
33. Zhang $N$, Kong $X$, Yan S, Yuan C, Yang Q: Huaier aqueous extract inhibits proliferation of breast cancer cells by inducing apoptosis. Cancer $\mathrm{SCi}$ 2010, 101(11):2375-2383

34. Toillon R-A, Chopin V, Jouy N, Fauquette W, Boilly B, Le Bourhis X: Normal breast epithelial cells induce p53-dependent apoptosis and p53-independent cell cycle arrest of breast cancer cells. Breast Cancer Res Treat 2002, 71(3):269-280.

35. Baell JB, Huang D: Prospects for targeting the $\mathrm{BCl}-2$ family of proteins to develop novel cytotoxic drugs. Biochem Pharmacol 2002, 64(5):851-863.

36. Goodsell DS: The molecular perspective: $\mathrm{Bcl}-2$ and apoptosis. Oncologist 2002, 7(3):259-260

37. Kluck RM, Bossy-Wetzel E, Green DR, Newmeyer DD: The release of cytochrome $\mathrm{c}$ from mitochondria: a primary site for $\mathrm{BCl}-2$ regulation of apoptosis. Science 1997, 275(5303):1132-1136.

38. Sedlak TW, Oltvai ZN, Yang E, Wang K, Boise LH, Thompson CB, Korsmeye SJ: Multiple $\mathrm{Bcl}-2$ family members demonstrate selective dimerizations with Bax. Proc Natl Acad Sci 1995, 92(17):7834-7838.

39. Elmore S: Apoptosis: a review of programmed cell death. Toxicol Pathol 2007, 35(4):495-516

40. Herceg Z, Wang Z-Q: Functions of poly (ADP-ribose) polymerase (PARP) in DNA repair, genomic integrity and cell death. Mutat Res-Fund Mol M 2001, 477(1):97-110.

41. Mantena SK, Baliga MS, Katiyar SK: Grape seed proanthocyanidins induce apoptosis and inhibit metastasis of highly metastatic breast carcinoma cells. Carcinogenesis 2006, 27(8):1682-1691

42. Dhillon A, Hagan S, Rath O, Kolch W: MAP kinase signalling pathways in cancer. Oncogene 2007, 26(22):3279-3290.

43. Yang $\mathrm{S}-\mathrm{H}$, Sharrocks $\mathrm{AD}$, Whitmarsh $\mathrm{A}$ : MAP kinase signalling cascades and transcriptional regulation. Gene 2013, 513(1):1-13.

44. Salminen A, Lehtonen M, Paimela T, Kaarniranta K: Celastrol: molecular targets of thunder god vine. Biochem Biophys Res Commun 2010, 394(3):439-442.

45. Gupta AK, Cerniglia GJ, Mick R, McKenna WG, Muschel RJ: HIV protease inhibitors block Akt signaling and radiosensitize tumor cells both in vitro and in vivo. Cancer Res 2005, 65(18):8256-8265.

46. Gupta AK, Li B, Cerniglia GJ, Ahmed MS, Hahn SM, Maity A: The HIV protease inhibitor nelfinavir downregulates Akt phosphorylation by inhibiting proteasomal activity and inducing the unfolded protein response. Neoplasia (New York, NY) 2007, 9(4):271.

doi:10.1186/1472-6882-14-387

Cite this article as: Shebaby et al:: Daucus carota pentane-based fractions arrest the cell cycle and increase apoptosis in MDA-MB-231 breast cancer cells. BMC Complementary and Alternative Medicine 2014 14:387

\section{Submit your next manuscript to BioMed Central and take full advantage of:}

- Convenient online submission

- Thorough peer review

- No space constraints or color figure charges

- Immediate publication on acceptance

- Inclusion in PubMed, CAS, Scopus and Google Scholar

- Research which is freely available for redistribution 